\title{
Spreading depression: Effects of applying potassium chloride to the dura of the rabbit on the conditioned nictitating membrane response'
}

\author{
James D. Papsdorf, Douglas Longman and I. Gormezano \\ INDIANA UNIVERSITY
}

\begin{abstract}
Abstraet
The nictitating membrane response of the rabbit was conditioned to an auditory CS with infra-orbital shock as the US. Following conditioning, Ss were divided into two groups to receive application to their exposed dura of either physiological saline or potassium chloride (KCl). Saline had no detectable effects, whereas $\mathrm{KCl}$ crystals blocked the occurrence of CRs for about 100 min. and was followed by recovery to approximately $70 \%$ of their initial level after $254 \mathrm{~min}$.

\section{Problem}

The interfering effects of cortical application of $\mathrm{KCl}$ has been demonstrated on instrumental avoidance responses with rats (Bureš et al, 1958; Tapp, 1962) and on operant responses with both rats (Russell \& Ochs, 1961) and pigeons (Shima, 1964). In these investigations $\mathrm{KCl}$ was employed as a technique for producing a reversible functional ablation through production of cortical spreading depression (SD). The electrophysiological manifestations of SD involves a marked decrement in amplitude of the EEG and reduced cortical sensitivity to evoked potentials (Leão, 1944). Although cortical application of $\mathrm{KCl}$ produces electrophysiological manifestations of SD in the rabbit (Van Harreveld \& Bogen, 1956), no data are available of its effects on learned behavior in this species. Furthermore, no assessment has been made of the effects of $\mathrm{KCl}$ on a classically conditioned response whereas, Tapp (1962) has suggested that much of the effects of $\mathrm{KCl}$ may be due to SD's interference with the complex motor coordination required for execution of an instrumental response. Consequently, the present investigation assessed the effects of $\mathrm{KCl}$ on the discrete, classically conditioned nictitating membrane response of the rabbit.
\end{abstract}

\section{Method}

Six albino rabbits, 90-100 days old, were anesthetized by peritoneal injection of Nembutal $(30 \mathrm{mg} / \mathrm{kg})$. The hair from S's scalp was removed and a 2-in midline incision was made to permit separation of the scalp. Exposure of the brain surfaces of both hemispheres was achieved by trephine openings $2 \mathrm{~mm}$ in diameter, situated $3 \mathrm{~mm}$ anterior to the coronal suture and $3 \mathrm{~mm}$ lateral to the saggital suture. Trephining was done carefully to avoid damage of the dura, stainless steel screws were threaded into the holes, and a wall of dental cement was constructed around the scalp wound to permit access to the holes. The hair around the infra-orbital region of S's right eye was then removed and two 9-mm stainless steel sutures were secured to the skin approximately 1 in caudal to the eye socket and approximately $3 / 4$ in apart.

The apparatus and preparation employed in conditioning the nictitating membrane response of the rabbit has been described (Schneiderman \& Gormezano, 1964). Briefly, $\mathrm{S}$ was placed in a Plexiglass restraining box with his head inserted through a stock. A muzzle-like assembly containing a rotary potentiometer was mounted on S's head and alligator-clip electrodes were attached to the sutures embedded in the skin. To permit recording of membrane movement the superior and inferior eyelids of S's right eye were held back by hooks. A silk thread was attached to a rod coupled to the shaft of the potentiometer and a hook connected to the other end of the thread was attached to a nylon loop sutured in the nictitating membrane of S's right. The signals from the potentiometer were then amplified and graphically recorded.

On the fourth and fifth day following surgery, Ss received $1-\mathrm{hr}$. adaptation sessions to the experimental enclosure and restraining box. On each of five subsequent daily sessions, Ss received $50 \mathrm{CS}$-US presentations at intertrial intervals of 40,60 and $80 \mathrm{sec}$. with a $1-\mathrm{min}$. average intertrial interval. The CS consisted of a $76 \mathrm{db}-$ 1000 cps tone against a continuously present white noise of $40 \mathrm{db}$. The US consisted of a $200 \mathrm{msec}$. shock of $3.0 \mathrm{ma}$ delivered through a constant current shock source and the CS-US interval was $500 \mathrm{msec}$. with the CS terminating at offset of the US. Prior to a sixth and seventh session the trephine screws were removed and the holes revised. The $\mathrm{S}$ was given $15 \mathrm{CS}-\mathrm{US}$ trials and then removed from the experimental enclosure. Three Ss selected at random received $.03 \mathrm{ml}$ of $25 \%$ $\mathrm{KCl}$ solution in both trephined holes, while the other three Ss received an equivalent amount of physiological saline. Four min. after treatment Ss received an additional 35 conditioning trials. On an eight session the procedure was similar except that after 15 conditioning trials the $\mathrm{KCl}$ group received $9 \mathrm{mg}$ of $\mathrm{KCl}$ crystals. Both groups then received an additional 195 CS-US trials, the last 100 trials of which were given at an average intertrial interval of $90 \mathrm{sec}$.

\section{Results and Diseussion}

The combined performance of the saline and $\mathrm{KCl}$ groups over the first five conditioning sessions is plotted in 50-trial blocks in Fig. 1. The figure reveals Ss attained a response level of about $92 \%$ by the third 


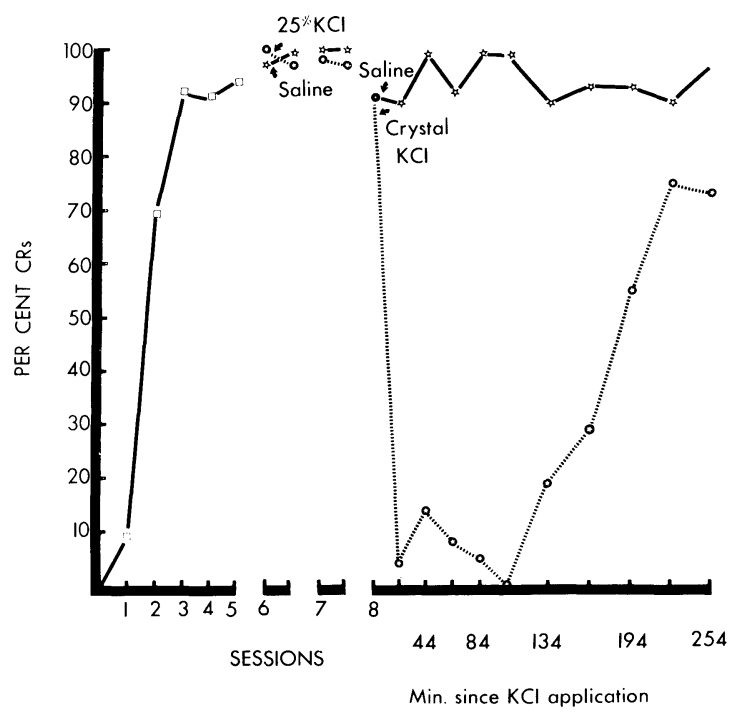

Fig. 1. Percentage CRs are plotted in 50-trial blocks over the first five sessions. The first data points of Sessions 6,7 and 8 represent performance for 15 trials preceding, and the second data points of Sessions 6 and 7, for 35 trials following chemical treatment. Data points following treatment on the eight session are based on 20 -trial blocks.

session, followed by a slight increase to $95 \%$ on the fifth session. The first data points of Sessions 6,7 and 8 represent the performance of the groups over the first 15 trials preceding chemical application, while the second data points of Sessions 6 and 7 represent their performance over the 35 trials following chemical application. As is apparent from the figure the $25 \%$ $\mathrm{KCl}$ and saline treatments had little detectable effects upon performance. Since the rabbit has a thicker dura and larger epidural space than the rat and pigeon (Bures, 1964) ${ }^{2}$ the concentration of $\mathrm{KCl}$ was increased on the eight session by applying $\mathrm{KCl}$ crystals. The data points following chemical application on the eight session are based on the performance of Ss over 20-trial blocks, while values on the abscissa denote elapsed time since application. By the fourth conditioning trial following application, complete loss of CRs was observed for all Ss in the $\mathrm{KCl}$ group whereas, there was no detectable decrement in performance for saline treatment Ss. In the $\mathrm{KCl}$ group level of responding dropped from
$91 \%$ to $4 \%$ in the first $24 \mathrm{~min}$. and stayed well under $20 \%$ for over $104 \mathrm{~min}$. The CR level increased gradually over the next $2 \mathrm{hr}$. to $72 \%$ after $254 \mathrm{~min}$. and the session was terminated at this point because of increased struggling of Ss.

In the present investigation the duration of blocking of CRs was longer than the 60-70 min. reported for the blocking effects of $25 \% \mathrm{KCl}$ by Bureš et al (1958) on an avoidance response in rats and the 40-50 min. observed by Shima (1964) on an operant response in pigeons. Although comparisons are confounded by both differences in species and the response learned, it is probable that the longer blocking time was due to the higher concentration of $\mathrm{KCl}$ crystals providing a more sustained infusion of $\mathrm{KCl}$ through the dura. It is also of interest to note that during the period of depression of CRs, the UCRs remained intact and showed no modification in response topography. More important perhaps, the regular occurrence of spontaneous membrane responses in the intertrial intervals during depression, indicated the response was intact and further weakens the thesis of Tapp (1962) that the effects of $\mathrm{KCl}$ on learned behavior operates through impairment of S's motor coordination.

\section{References}

BUREŠ, J., BUREŠOVA, O., \& ZÁHOROVÁ, A. Conditioned reflexes and Leáo's spreading cortical depression. J. comp. physiol. Psychol., 1958, 51, 263-268.

LEÄO, A. A. P. Spreading depression of activity in the cerebral cortex. J. Neurophysiol., 1944, 7, 359-390.

RUSSELL, I. S., \& OCHS, S. One-trial interhemispheric transfer of a learning engram. Science, 1961, 13, 1077-1078.

SCHNEIDERMAN, N., \& GORMEZANO, I. Conditioning of the nictitating membrane of the rabbit as a function of CS-US interval. J. comp. physiol. Psychol., 1964, 57, 188-195.

SHIMA, I. Behavioral consequences of striatal spreading depression in pigeons. J. comp. physiol. Psychol., 1964, 57, 37-41.

TAPP, J. T. Reversible cortical depression and avoidance behavior in the rat. J. comp. physiol. Psychol., 1962, 55, 306-308.

VAN HARREVELD, A., \& BOGEN, J. E. Regional differences in propagation of spreading cortical depression in the rabbit. Proc. Soc. Exp. Biol. \& Med., 1956, 91, 297-302.

Notes

1. This research was supported by Predoctoral Fellowship MH-24, 756-01 (J. Papsdorf) from the National Institute of Mental Health and Grant GB-2843 (I. Gormezano) from the National Science Foundation.

2. J. Bureš, personal communication, 1964. 